\title{
Government Expenditure and Economic Growth in Iran
}

\author{
Mohsen Mehrara ${ }^{*}$, Hamid Abrishami ${ }^{* *}$, Mostafa Boroujli ${ }^{* \star *}$, Mahan Amin ${ }^{\star \star * *}$ \\ Faculty of Economics, University of Tehran, Kargar-e-shomali, Po Box 14166-6445, Tehran, Iran

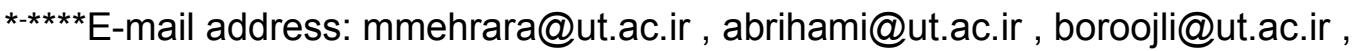 \\ m.amin@ut.ac.ir
}

\begin{abstract}
This paper examines causal relationships between Government Recurrent Expenditure (GRE) and GDP for Iran using annual data over the period 1970-2010. The Gregory-Hansen (1996) cointegration technique, allowing for the presence of potential structural breaks in data, is applied to empirically examine the long-run co-movement between these variables. The results suggest that there is a long-run relationship between these variables. The Granger Causality test indicates strong unidirectional effects from GDP to GRE. But there is no evidence that TRE promotes long-term economic growth. Moreover, the main results in this paper confirm that there is an instantaneous as well as unidirectional causal link running from GDP to GRE. Based on the results, the policy makers should ensure that recurrent expenditures are properly managed to accelerate economic growth. Moreover, government should promote efficiency in the allocation of resources by encouraging more private sector participation to ensure productivity-intensive growth.
\end{abstract}

Keywords: Unit root; Cointegration, Granger Causality; Government Recurrent Expenditure; Economic Growth

JEL classifications: $\mathrm{C} 12 ; \mathrm{C} 22 ; \mathrm{C} 52 ; \mathrm{E} 21 ; \mathrm{F} 43$

\section{INTRODUCTION}

Public expenditure including recurrent and capital expenditure can be growth-enhancing although providing essential infrastructures including transport, electricity, telecommunications, water and sanitation, waste disposal, education and health. Moreover these expenditures can be growth-retarding (for example, the negative effect associated with taxation and excessive debt). The impact of government expenditure on economic growth is still an unsettled topic theoretically as well as empirically (Grossman, 1988). However, two approaches to public expenditure have been launched in literature: Wagner's and Keynes approach.

The Wagner's law predicts that as income per capita increases, the share of the public sector in the national economy grows continually (Musgrave and Musgrave, 1988). The Wagner's approach implies that government expenditures are endogenous to economic development. 
Wagner identified three key reasons for increased government spending. First, administrative and protective role of government will rise as a country's economy develops. Second, with expansion of an economy, government welfare expenditures would raise, particularly on education and health. He implicitly assumed that the income elasticity of demand for public goods is more than unity. Finally, progress in technology requires government to take on certain economic services for which private sector may downside (Cooray, 2009).

The second proposition is associated with Keynesians. To Keynes, public expenditure is an exogenous factor and a policy instrument for increasing national income. Consequently, he supposes that the causality of the relationship between public expenditure and national income runs from expenditure to income. Moreover, Governments performs two functions- protection (and security) and provisions of certain public goods (Abdullah, 2000). Protection function consists of the rule of law and enforcement of property rights. This helps to minimize risks of criminality, protect life and property, and the nation from external aggression. The provisions of public goods include defense, roads, education, health, and power, to mention few. Some scholars argue that increase in government expenditure on socio-economic and physical infrastructures promotes economic growth. For example, government expenditure on health and education raises the productivity of labor and increase the growth of national output. Similarly, expenditure on infrastructure such as roads, communications, power, etc, reduces production costs, increases private sector investment and profitability of firms, thus encouraging economic growth. Supporters of this view, concluded that expansion of government expenditure contributes positively to economic growth.

However, some researchers maintain the claim that increasing government expenditure threat economic growth, and higher expenditure may shrink performance of the economy. For example, in an attempt to finance growing expenditure, government may raise taxes and/or borrowing. Higher tax discourages firms and laborers, reducing investment, income and demand. Moreover, if government increases borrowing (especially from the banks) in order to finance its expenditure; it will crowd out the private sector, leading to reducing private investment. Furthermore, in a tender to remain in power, politicians and governments officials sometimes increase expenditure and investment in unproductive plans or in goods that the private sector can manufacture more efficiently.

Given the issues raised above, this paper examines the causal relationship between government recurrent expenditure and economic growth in Iran during 1970-2010. Section 2 discusses the methodology and data. We also present the empirical results of the paper in section 2, and section 3 concludes.

\section{METHODOLOGY AND EMPIRICAL RESULTS}

In this section we use the Granger causality to study the causal relationship between government recurrent expenditure and economic growth in Iran. The macroeconomic variables used in the model are (logarithm of) real government recurrent expenditure (GRE) and real GDP (GDP). The data series are obtained from Central Bank of Iran (CBI). The data are annual from 1970-2010, reflecting data availability. Considering the short sample period, a bivariate model is used to empirically examine the long-run co-movement and the causal relationship between government recurrent expenditure and real GDP. 


\section{1. Zivot and Andrews Unit Root Test}

Conventional tests for identifying the existence of unit roots in a data series include that of the Augmented Dickey Fuller (ADF) $(1979,1981)$ or Phillips-Perron(1988). So in the first step of the empirical analysis, the Phillips - Perron unit-root tests have been carried out for the both variables: government recurrent expenditure and GDP, both in logarithm. The results reported in Table 1, indicate that both of the variables are nonstationary. However, recent contributions to the literature suggest that such tests may incorrectly indicate the existence of a unit root, when in actual fact the series is stationary around a one-time structural break (Zivot and Andrews, 1992; Pahlavani, et al, 2006). Zivot and Andrews (ZA) (1992) argue that the results of the conventional unit root tests may be reversed by endogenously determining the time of structural breaks. The null hypothesis in the Zivot and Andrews test is a unit root without any exogenous structural change. The alternative hypothesis is a stationary process that allows for a one-time unknown break in intercept and/or slope. Following Zivot and Andrews, we test for a unit root against the alternative of trend stationary process with a structural break both in slope and intercept. Table 1 provides the results. As in the Phillips-Perron case, the estimation results fail to reject the null hypothesis of a unit root for both variables. The same unit root tests have been applied to the first difference of the variables and in all cases we rejected the null hypothesis of unit root. Hence, we maintain the null hypothesis that each variable is integrated of order one or I(1).

Table 1. Unit-root tests of Phillips-Perron(PP) and Zivot and Andrews (ZA).

\begin{tabular}{ccrrr}
\hline \multicolumn{2}{c}{ Government Recurrent Expenditure (GRE) } & & \multicolumn{2}{c}{ Real GDP } \\
\cline { 1 - 2 } \cline { 5 - 5 } PP & ZA & & PP & ZA \\
\hline-0.83 & $-1.48(1979)$ & & -1.69 & $-1.88(1979)$ \\
\hline
\end{tabular}

Note: The break point in ZA unit root test is presented in brackets. Empirical results fail to reject the null hypothesis of unit-root in all cases. The lag lengths for the ZA and PP tests are chosen by using SC's information criterion and Newey and West (1987) method respectively. Critical values for ZA tests were obtained from Zivot and Andrews (1992). Break points are reported in ( )

\section{2. The Gregory-Hansen Cointegration Analysis}

Cointegrationtest means looking for a stationary long-run relationship between nonstationary variables. It has been introduced for the first time in 1980's by Engle and Granger (1987), Johansen $(1988,1991)$, Johansen and Jeslius $(1990,1992)$ and the others. There are some methods for testing for cointegration the most well-known of which is Johansen test. However, as noted by Perron (1989), ignoring the issue of potential structural breaks can render invalid the statistical results not only of unit root tests but also of cointegration tests. Kunitomo (1996) argues that in the presence of a structural change, traditional cointegration tests, which do not allow for this, may produce spurious cointegration. Therefore one has to be aware of the potential effects of structural effects on the results a cointegration test, as they usually occur because of major policy changes or external shocks in the economy.

The Gregory-Hansen approach (1996) (hereafter, GH) addressed the problem of estimating cointegration relationships in the presence of a potential structural break by introducing a residual-based technique so as to test the null hypothesis (no cointegration) 
against the alternative of cointegration in the presence of the break (such as a regime shift). In this approach the break point is unknown, and is determined by finding the minimum values for the ADF t-statistic. By taking into account the existence of a potential unknown and endogenously determined one-time break in the system, $\mathrm{GH}$ introduced three alternative models. The first model includes intercept or constant (C) and a level shift dummy. The second alternative model $(\mathrm{C} / \mathrm{T})$ contains an intercept and trend with a level shift dummy. The third model is the full break model $(\mathrm{C} / \mathrm{S})$, which includes two dummy variables, one for the intercept and one for the slope, without including trend in model. This model allows for change in both the intercept and slope.

These tests detect the stability of cointegrating vectors over time in the presence of structural breaks in the form of level shift, level shift with trend, and regime shift. Table 2 reports all cases. when dependent variable is government recurrent expenditure, the null hypothesis of no cointegration relationships is rejected in favor of the existence of one cointegrating relationship, allowing for a one time structural break (although not rejected when GDP is dependent variable). The results show that the variables under examination do not drift apart for Iran. The estimated long run relationship using the $\mathrm{C} / \mathrm{S}$ is of the form:

$$
\begin{aligned}
& \text { GRE }=1.12+2.52 G D P-2.64 D-0.83 D(G D P)-0.004 \text { trend } \\
& t \quad(5.45)(5.42) \quad(4.55) \quad(6.65)
\end{aligned}
$$

where dummy $D=0$ if $t \leq 1979$ and $D=1$ if $t>1979$.

Table 2. Gregory-Hansen cointegration tests.

\begin{tabular}{|c|c|c|c|}
\hline $\begin{array}{c}\text { Dependent } \\
\text { Variable }\end{array}$ & Model & Test Statistic & Break Point \\
\hline GRE & $\mathrm{C}$ & $-6.45^{*}$ & 1980 \\
& $\mathrm{C} / \mathrm{T}$ & $-5.74^{*}$ & 1979 \\
& $\mathrm{C} / \mathrm{S}$ & $-4.65^{*}$ & 1980 \\
\hline GDP & $\mathrm{C}$ & -1.81 & 1979 \\
& $\mathrm{C} / \mathrm{T}$ & -0.92 & 1979 \\
& $\mathrm{C} / \mathrm{S}$ & -1.51 & 1980 \\
\hline
\end{tabular}

Notes: $\mathrm{C}$ denotes level shift, $\mathrm{C} / \mathrm{T}$ denotes level shift with trend, and $\mathrm{C} / \mathrm{S}$ denotes regime shift. The lag length is chosen based on minimum SC.* denotes significant at the $5 \%$ level. Critical values were obtained from Gregory and Hansen (1996).

Both the intercept and the intercept at the time of regime shift (Islamic Revolution in Iran) are significant. Moreover, the income elasticity of government recurrent expenditure before the regime shift and at the time of regime shift is significant. The income elasticity before the regime shift is 2.52 , far more than unity. It decreases by 0.83 with regime shift. Therefore, we can see that income elasticity has decreased after regime shift and took a different path, 
implying more inclination to cutting government expenditure after the revolution. So, the income elasticity of government recurrent expenditure in Iran, after the Islamic revolution amount to 1.69 significantly more than unity, implying that government recurrent expenditure progressively increase when income increase.

\section{3. Granger Causality Tests}

The existence of cointegrating relationship between GRE and GDP for Iran suggests that there must be long run Granger causality in at least one direction (Hatanaka, 1996). In this section, we test for Granger Causality between log of real government recurrent expenditure (GRE) and log of real GDG per capita (GDP). Cointegration implies that causality exists between the two series but it does not indicate the direction of the causal relationship. The dynamic Granger causality can be captured from the vector error correction model (VECM) derived from the long-run cointegrating relationship (Granger 1988). Engle and Granger (1987) showed that if the two series are cointegrated, the vector-error correction model for the GRE and GDP series can be written as follows:

$$
\begin{aligned}
& \Delta G R E=\alpha_{y}+\beta_{G} E C T_{t-1}+\sum_{i=1}^{n} \gamma_{G i} \Delta G D P_{t-i}+\sum_{i=1}^{n} \delta_{G i} \Delta G R E_{t-i}+\varepsilon_{G i} \\
& \Delta G D P=\alpha_{y}+\beta_{y} E C T_{t-1}+\sum_{i=1}^{n} \gamma_{y i} \Delta G D P_{t-i}+\sum_{i=1}^{n} \delta_{y i} \Delta G R E_{t-i}+\varepsilon_{y i} \\
& E C T=G R E-1.12-2.52 G D P+2.64 D+0.83 D(G D P)+0.004 \text { trend }
\end{aligned}
$$

where $\Delta$ is a difference operator; ECT is the lagged error-correction term derived from the long-run cointegrating relationship; The $\beta(i=y, G)$ are adjustment coefficients; a is long run coefficient or elasticity and the $\varepsilon_{i t} s$ are disturbance terms assumed to be uncorrelated and random with mean zero.

Sources of causation can be identified by testing for significance of the coefficients on the lagged variables in Eqs. (1) and (2). First, by testing $H_{0}: \gamma_{\alpha}=0$ for all $\mathrm{i}$ in Eq. (1) or $H_{0}: \delta_{x}=0$ for all $\mathrm{i}$ in Eq. (2), we evaluate Granger weak causality. This can be implemented using a standard F-test. Masih and Masih (1996) and Asafu-Adjaye (2000) interpreted the weak Granger causality as 'short run' causality in the sense that the dependent variable responds only to short-term shocks to the stochastic environment.

Another possible source of causation is the ECT in Eqs. (1) and (2). In other words, through the ECT, an error correction model offers an alternative test of causality (or weak exogeneity of the dependent variable). The coefficients on the ECTs represent how fast deviations from the long run equilibrium are eliminated following changes in each variable. If, for example, $\beta_{n}$ is zero, then GRE does not respond to a deviation from the long run equilibrium in the previous period. Indeed $\beta_{c}=0$ or $\beta_{y}=0$ is equivalent to both the Granger non-causality in the long run and the weak exogeneity (Hatanaka, 1996). This can be tested using a simple t-test.

It is also desirable to check whether the two sources of causation are jointly significant, in order to test Granger causality. This can be done by testing the joint hypotheses $H_{0}: \beta_{R}=0$ and $\gamma_{\alpha}=0$ for all $\mathrm{i}$ in Eq. (1) or $H_{0}: \beta=0$ and $\delta_{y}=0$ for all $\mathrm{i}$ in Eq.(2). This is referred to as a strong Granger causality test. The joint test indicates which variable(s) bear the burden of short 
run adjustment to re-establish long run equilibrium, following a shock to the system (AsafuAdjaye, 2000). A test of these restrictions can be done using F-tests.

Another concept related to Granger-causality is that of instantaneous causality. Roughly speaking, a variable GRE is said to be instantaneously causal for another time series variable GDP if knowing the value of GRE in the forecast period helps to improve the forecasts of GDP. It turns out, however, that in a bivariate VAR process, this concept reduces to a property of the model residuals. More precisely, let $\varepsilon_{i}=\left(\varepsilon_{\alpha}, \varepsilon_{x}\right)$ be the residual vector of $y_{i}=(\triangle G R E, \triangle G D P)$; then, $\triangle G R E$ is not instantaneously causal for $\triangle G D P$ if and only if $\varepsilon_{x}$ and $\mathrm{u} \varepsilon_{c i}$ are uncorrelated. In turn, $\triangle G R E$ is instantaneously causal for $\triangle G D P$ if and only if $\varepsilon_{a}$ and $\varepsilon_{n}$ are correlated. Consequently, the concept is fully symmetric. If $\triangle G D P$ is instantaneously causal for $\Delta I N V$, then $\triangle I N V$ is also instantaneously causal for $\triangle G D P$. Hence, the concept as such does not specify a causal direction. The causal direction must be known from other sources. Still, if it is known from other sources that there can only be a causal link between two variables in one direction, it may be useful to check this possibility by considering the correlation between the residuals (Lutkepohl, 2004).

The results of the tests on causality are presented in Table 3. The evidence strongly indicates that GDP Granger-causes GRE. The coefficient of the ECT and lagged explanatory variables are significant in the GRE equation which indicates that long-run as well as short run causalities run from GDP to GRE. The adjustment coefficient in GRE equation (2) is estimated about -0.72 . It means that GRE adjusts at a reasonable speed to the long-run equilibrium, where almost four-fifth of the disequilibrium is corrected in the first period. Moreover, the interaction term (ECT and GDP) in the spending equation is significant at $5 \%$ level. The results for the other equation suggest that GRE has no effect on GDP in short- and long-run. Therefore, there is unidirectional Granger causality running from GDP to GRE.

Table 3. Result of causality tests.

\begin{tabular}{|c|c|c|c|c|c|}
\hline \multirow{4}{*}{ Null hypothesis } & \multicolumn{5}{|c|}{ Source of causation } \\
\hline & \multicolumn{2}{|c|}{ Short-run } & \multirow{2}{*}{$\begin{array}{l}\text { Long-run } \\
E C T(-1)\end{array}$} & \multicolumn{2}{|c|}{$\begin{array}{l}\text { Joint(short-run/long- } \\
\text { run) }\end{array}$} \\
\hline & $\triangle G R E$ & $\triangle G D P$ & & $\begin{array}{l}\triangle G R E \\
E C T(-1)\end{array}$ & $\begin{array}{l}\triangle G D P \\
E C T(-1)\end{array}$ \\
\hline & $\begin{array}{c}\text { F- } \\
\text { statistics }\end{array}$ & & $\begin{array}{c}\mathrm{t}- \\
\text { statistics }\end{array}$ & $\begin{array}{c}\text { F- } \\
\text { statistics }\end{array}$ & \\
\hline $\begin{array}{l}\text { GRE does not cause GDP } \\
\text { p-value }\end{array}$ & $\begin{array}{l}0.87 \\
(0.71)\end{array}$ & - & $\begin{array}{l}-1.11 \\
(0.49)\end{array}$ & $\begin{array}{l}1.32 \\
(0.40)\end{array}$ & - \\
\hline $\begin{array}{l}\text { GDP does not cause GRE } \\
\text { p-value }\end{array}$ & - & $\begin{array}{c}6.54 \\
(0.00)\end{array}$ & $\begin{array}{l}-6.99 \\
(0.00)\end{array}$ & - & $\begin{array}{c}9.53 \\
(0.00)\end{array}$ \\
\hline
\end{tabular}

Notes: the lag length has been chosen based on minimum SC. $\Delta$ denotes series in first difference.

Testing for instantaneous causality can be done by determining the absence of instantaneous residual correlation. Because only one correlation coefficient is tested to be zero, the number of degrees of freedom of the approximating chi-square distribution is one. Clearly, it is sufficient to report the test result for only one instantaneous causal direction because the 
test value for the other direction is identical given that it tests the very same correlation coefficient. The test statistics based on the residuals of the VECM is 12.65, being highly significant. These results imply that, there is instantaneous as well as unidirectional Granger causality running from GDP to GRE, while government recurrent expenditure has an insignificant effect on GDP in both the short- and long-run. In other words, GRE is strongly exogenous and whenever a shock occurs in the system, GRE must be reduced to maintain the long run relationship.

\section{CONCLUSION}

This paper applies Gregory-Hansen (1996) cointegration and error correction modeling techniques in order to test causal relationship between government recurrent expenditure(GRE) and real GDP in Iran based on annual data from 1970 to 2010. Prior to cointegration analysis, the Zivot and Andrews unit root test has been applied to test the stationarity of the variables. The empirical results indicate that we cannot find enough evidence against the null hypothesis of unit root. However, for the first difference of the variables, we rejected the null hypothesis of unit root. It means that the variables are I(1). The results show that there is a long-run relationship between GRE and GDP.

The value of the income elasticity before the regime shift is 2.52 , much more than unity, while it comes to 1.69 , yet significantly more than unity, after the Islamic revolution recognized as the second regime. It means that government recurrent expenditure progressively increase with income in the both regimes. We also find strong support for the exogeneity of GDP. The main results in this paper confirm that there is an instantaneous and unidirectional causal link running from GDP to GRE. Our findings also indicate that government expenditures does not play a significant role in promoting economic growth in Iran. The government should ensure that recurrent expenditures are properly managed to accelerate economic growth. Moreover, government should promote efficiency in the allocation of resources by encouraging more private sector participation to ensure productivity-intensive growth.

\section{Acknowledgements}

The authors would like to acknowledge the financial support of university of Tehran for this research under the grant number 4401012/1/22.

\section{References}

[1] Abdullah H., Journal of Administrative Science 12(2) (2000) 173-191.

[2] Al-Yousif Y., Does Government Expenditure Inhibit or Promote Economic Growth: Some Empirical Evidence from Saudi Arabia. Indian Economic Journal 48(2) (2000).

[3] Cooray A., Comparative Economic Studies 51(3) (2009) 401-418, [http://www.ingentaconnect.com/content/pal/ces;jsessionid=q1g81gkzfvms.alice]

[4] Dickey D., Fuller W., Journal of the American Statistical Association 74 (1979) 427-431.

[5] Dickey, D. A., W. A. Fuller, Econometrica 49(1981) 1057-1072.

[6] Engle R. F., Granger C. W. J., Econometrica 55(2) (1987) 987-1008. 
[7] Granger C. W. J., Econometrica 37(3) (1969) 424-438.

[8] Granger C. W. J., Journal of Econometrics 39 (1988) 199-211.

[9] Gregory Allan W., Hansen Bruce E., Journal of Econometrics 70(1) (1996) 99-126.

[10] Hatanaka M., (1996). Time-Series-Based Econometrics: Unit Roots and Cointegration, Oxford University Press.

[11] Johansen S., Journal of Economic Dynamics and Control 12(2-3) (1988) 231-254.

[12] Johansen S., Econometrica 59(6) (1991) 1551-1580.

[13] Johansen S., Jeslius K., Oxford Bulletin of Economics and Statistics 52(2) (1990) 169-210.

[14] Johansen S., Juselius K., Journal of Econometrics 53 (1992) 211-244.

[15] Kaldor, N., Review of Economic Studies 23(2) (1956) 83-100.

[16] Kunitomo N. (1996). Tests OF Unit roots and Cointegration Hypotheses in Econometric Models, 47(1), pp. 79-109.

[17] Lewis W. A. (1955). The Theory of Economic Growth, Irwin, Homewood

[18] Lutkepohl H. (2004). Vector Autoregressive and Vector Error Correction Model, in Lutkepohl, H. and M. Kratzig (ed.), Applied Time Series econometrics, Cambridge University Press.

[19] Masih A. M. M., R. Masih, Energy Economics 18 (1996) 165-183.

[20] Asafu-Adjaye J., Energy Economics 22 (2000) 615-625.

[21] Samuelson P., Modigiani P., Review of Economic Studies 33 (1966) 269-301.

[22] Pahlavani M., Wilson E. J., A. Valadkhani, International Journal of applied Business and Economic Research 4(1) (2006) 23-44.

[23] Perron P., Econometrica 57 (1989) 1361-1401.

[24] Phillips P. C. B., Perron P., Biometrica 75 (1988) 335-346.

[25] Ranjan K., Sharma C., The ICFAI University Journal of Public Finance 6(3) (2008) 60-69.

[http://ssrn.com/abstract=1216242]

[25] Zivot, E., Andrews, D., Journal of Business and Economic Statistics 10 (1992) 251-70. 